\title{
Aerosolized surfactant inhibits acetylcholine-induced airway obstruction in rats
}

\author{
J. Hohlfeld*+, H.G. Hoymann+, J. Molthan+, H. Fabel*, U. Heinrich+
}

\begin{abstract}
Aerosolized surfactant inhibits acetylcholine-induced airway obstruction in rats. J. Hohlfeld, H.G. Hoymann, J. Molthan, H. Fabel, U. Heinrich. CERS Journals Ltd 1997. ABSTRACT: Exogenous surfactant treatment inhibits antigen-induced airway obstruction in sensitized guinea-pigs. Aerosolized surfactant also improves respiratory function in asthmatic patients. The aim of the present study was to determine whether aerosolized surfactant inhibits nonallergic airway obstruction induced by acetylcholine.

Anaesthetized Wistar rats were treated by aerosol with the $\beta_{2}$-adrenoceptor agonist terbutaline, surfactant (Alveofact ${ }^{\circledR}$ ), a surfactant-terbutaline combination, or vehicle (control). Animals were then challenged by aerosolized acetylcholine to elicit receptor-mediated airway obstruction. A second group of animals was challenged with intravenous acetylcholine. Respiratory function variables were measured by body plethysmography before and after treatment, and after the acetylcholine challenge.

Baseline lung function values before and after treatment were similar in all groups. Acetylcholine challenge by aerosol increased lung resistance by $64 \%$ in control animals. Pretreatment with terbutaline and surfactant significantly limited the increase of lung resistance to +36 and $+34 \%$, respectively. Simultaneous aerosolization of surfactant and terbutaline also inhibited airway obstruction but their effects were not additive. By contrast, terbutaline treatment inhibited the effects of intravenous acetylcholine, but surfactant did not.

In conclusion, we suggest that surfactant aerosol may prevent acetylcholine and other pharmacological agents from reaching the airway smooth muscle from the airway lumen but not via the bloodstream.

Eur Respir J 1997; 10: 2198-2203.
\end{abstract}

There is increasing evidence that pulmonary surfactant plays an important role in maintaining the patency and stability of small airways [1-4]. Furthermore, surfactant improves bronchial clearance [5], and modulates the function of respiratory inflammatory cells [6]. Disturbed surfactant function might, thus, have an impact on obstructive lung diseases.

Pathophysiologically, obstructive lung diseases are characterized by smooth muscle contraction, enhanced secretion of mucus, mucous plugging, oedema of the airway walls, exudation of a proteinaceous fluid, and impaired mucociliary clearance [7]. Some of these processes may inhibit surfactant functions, e.g. exuded protein may inhibit the surface activity [8], and accumulated fluid and mucus may dilute and alter the normal surfactant layer. Thus, exogenous surfactant therapy might be helpful in obstructive pulmonary disorders. In recent studies, intrabronchial surfactant instillation inhibited allergic bronchoconstriction in guinea-pigs $[9,10]$. Furthermore, inhaled surfactant improved lung function in patients suffering from acute asthma attacks [11].

However, the exact mechanisms by which surfactant relieves airway obstruction are unclear. To further evaluate this question, we studied the effects of aerosolized surfactant on nonallergic acetylcholine (ACh)-induced airflow obstruction.
+Fraunhofer Institute of Toxicology and Aerosol Research, Hannover, Germany. *Dept of Respiratory Medicine, Hannover Medical School, Germany.

Correspondence: J. Hohlfeld

Dept of Respiratory Medicine

Hannover Medical School

Carl-Neuberg-Str. 1

D-30625 Hannover

Germany

Keywords: Aerosol asthma

bronchoconstriction

inhalation

obstructive lung disease

pulmonary surfactant

Received: July 301996

Accepted after revision June 161997

\section{Materials and methods}

\section{Animals}

Female Wistar rats (Charles River Wiga GmbH, Sulzfeld, Germany), 26-31 weeks old and weighing 350$450 \mathrm{~g}$, were used in these experiments. Animals were housed, watered and fed as described previously [12, 13].

\section{Study design}

Respiratory function variables, including forced expiratory functions, were measured in anaesthetized, intubated, spontaneously breathing rats by body plethysmography. Therefore, animals were anaesthetized with halothane/ $30 \%$ oxygen and intubated orally with a tracheal cannula (Cathlon; Jelco Raritan, NJ, USA: $52 \mathrm{~mm}, 1.78 \mathrm{~mm}$ inner diameter). Rats were then placed in a body plethysmograph in supine position. They were allowed to stabilize for $5 \mathrm{~min}$, before baseline lung function variables were measured. Animals were then treated for $15 \mathrm{~min}$ with either aerosolized Ringer's solution ("control", $n=9$ ), surfactant ("surfactant", $20 \mu \mathrm{M}, \mathrm{n}=8$ ), terbutaline ("low 
terbutaline", $1.2 \mathrm{mM}, \mathrm{n}=8$; and "high terbutaline", 2.4 $\mathrm{mM}, \mathrm{n}=5$ ), or a surfactant-terbutaline combination ("combination", $20 \mu \mathrm{M}$ surfactant $+1.2 \mathrm{mM}$ terbutaline, $\mathrm{n}=8$ ), followed by a second measurement of pulmonary function. Directly thereafter, airway obstruction was induced by inhalation of aerosolized ACh $(278 \mathrm{mM})$ for $4 \mathrm{~min}$, followed by a third measurement of lung function. Preceding dose-response experiments were performed to find terbutaline-concentrations with moderate inhibitory effects on the ACh-induced airway obstruction, to ascertain possible additive effects in the surfactant-terbutaline group.

In a second series of experiments, airway obstruction was elicited by intravenous infusion of $0.33 \mathrm{~mL} \cdot \mathrm{kg}^{-1}$ $\mathrm{ACh}$ at a constant rate for $10 \mathrm{~s}$, via a tail vein catheter. Increasing concentrations of ACh (3.6, 4.9 and 7.2 mM) were given until airway resistance had increased by at least $50 \%$. Treatment with aerosolized surfactant, terbutaline, or vehicle control ( $\mathrm{n}=4$ each) was performed as described above. Thereafter, a second intravenous ACh challenge was performed.

Cardiac frequency was measured by electrocardiography throughout the study. Animals in all treatment groups were studied on each study day in randomized order.

\section{Pulmonary function measurements}

Spontaneous pulmonary function variables were determined as described recently $[12,13]$. They were recorded continuously and evaluated at baseline, pre- and post-treatment and pre- and post-ACh challenge. The variables measured included tidal volume $(V \mathrm{~T})$, dynamic lung compliance $(C$ dyn $)$ and lung resistance $(R \mathrm{~L})$. Forced lung function variables (forced vital capacity (FVC), forced expiratory volume in one hundred milliseconds (FEV0.1), peak expiratory flow (PEF), maximum midexpiratory flow (MMEF), and flow at 75, 50 and $25 \%$ of FVC (FEF75, FEF50 and FEF25, respectively)) were measured during hyperventilation-induced temporary apnoea, before and after treatment, and after ACh challenge $[12,13]$. In addition, pressure-volume curves and functional residual capacity (FRC) were derived as described previously [12], and allowed calculation of quasistatic compliance ( $C \mathrm{qs})$, total lung capacity (TLC), and residual volume $(\mathrm{RV})$.

\section{Aerosol generation and monitoring}

Aerosols were generated by jet nebulizer (Bronchy$\mathrm{H}$; Fraunhofer Institute of Toxicology and Aerosol Research, Hannover, Germany), which included systems for monitoring mass concentration (light-scattering photometer; Fraunhofer Institute of Toxicology and Aerosol Research, Hannover, Germany) and the dose delivered. The nebulizer was driven by an airflow of $3 \mathrm{~L} \cdot \mathrm{min}^{-1}$, and solutions were pumped through the jet at $2.4 \mathrm{~mL} \cdot \mathrm{h}^{-1}$. These limits gave efficient aerosol generation, minimized loss of test compounds and indirectly allowed adjustment of particle size.

ACh was aerosolized with a common jet (Pari-Boy®; Pari, Starnberg, Germany) driven by the Bronchy-H. All animals inhaled a total volume (particles plus carrier gas) of $600 \mathrm{~mL}$ aerosol, corresponding to $100 \mathrm{nmol}$ inhaled ACh. The treatment compounds were aerosolized with a similar generation device (Bronchy-II; Fraunhofer Institute of Toxicology and Aerosol Research), but a specially constructed jet was used to aerosolize surfactant efficiently (jet-No. 18; Fraunhofer Institute of Toxicology and Aerosol Research). Treatment compounds were inhaled for about $15 \mathrm{~min}$, until the chosen dose had been delivered. The amount of inhaled surfactant was $57.3 \mathrm{nmol}$ phospholipids $(43.5 \mu \mathrm{g})$, "low terbutaline" $4.4 \mathrm{nmol}$ and "high terbutaline" $8.8 \mathrm{nmol}$ per animal. Aerosol characteristics are presented in table 1.

\section{Measurement of surface activity}

Surface activity of surfactant material was measured with a pulsating bubble surfactometer (PBS) [14]. Briefly, PBS experiments were performed at a hypophase concentration of $4 \mathrm{mg}$ phospholipids. $\mathrm{mL}^{-1}$. Therefore, aerosolized surfactant was led into Ringer's solution ("aerosolized"). The same amount of surfactant was directly diluted into Ringer's solution ("diluted"). Surfactant was then obtained for oscillating bubble measurements by high speed centrifugation $(20,000 \times \mathrm{g}$ for 60 $\mathrm{min})$ to pellet the surfactant material and was resuspended at $4 \mathrm{mg} \cdot \mathrm{mL}^{-1}$.

\section{Drugs and solutions}

Compounds were freshly prepared daily. Surfactant (Alveofact ${ }^{\circledR}$; K. Thomae GmbH, Biberach an der Riss, Germany) was suspended and diluted in Ringer's solution at a final concentration of $15 \mathrm{mg}$ phospholipids $\cdot \mathrm{mL}^{-1}$ $(20 \mu \mathrm{M})$. Terbutaline (Sigma, Munich, Germany) was diluted in Ringer's solution at concentrations of $1.2 \mathrm{mM}$ ("low terbutaline") and $2.4 \mathrm{mM}$ ("high terbutaline"). Acetylcholine (Sigma, Munich, Germany) was dissolved in distilled water $(278 \mathrm{mM})$. Ringer's solution (RingerLösung DAB7 Braun; Braun Melsungen, Melsungen, Germany) contained $\mathrm{Na}^{+} 147 \mathrm{mM}, \mathrm{K}^{+} 4 \mathrm{mM}, \mathrm{Ca}^{2+} 2.3$ $\mathrm{mM}$ and $\mathrm{Cl}^{-} 155.5 \mathrm{mM}$.

\section{Statistical analysis}

Results are expressed as mean \pm SEM. Statistical differences between mean values of treatment groups were determined by analysis of variance (ANOVA) followed by the Fisher protected least significant difference test

Table 1. - Aerosol characteristics of the test compounds

\begin{tabular}{lcc}
\hline \multicolumn{1}{c}{$\mathrm{MMAD}^{\#}$} & $\begin{array}{c}\text { Concentration } \\
\mathrm{mg} \cdot \mathrm{m}^{-3}\end{array}$ \\
\hline Ringer's solution & $1.21(1.71)$ & 29.4 \\
Low terbutaline & $1.17(1.90)$ & 30.8 \\
High terbutaline & $1.25(2.61)$ & 33.0 \\
Surfactant & $1.33(1.85)$ & 68.3 \\
Combination & $1.19(1.72)$ & 69.3 \\
Acetylcholine & $1.36(1.80)$ & 32.7 \\
\hline
\end{tabular}

\#: mass median aerodynamic diameter (MMAD), with geometric standard deviation in parenthesis, was determined by cascade impactor. Aerosol concentration (total solids, salts plus drugs) was calculated by filter sampling. 
for comparison of different means [15]. Differences of changes after treatment and challenge in comparison to baseline within a certain group were tested for their statistical significance by paired t-test. A p-value of less than 0.05 was considered significant.

\section{Results}

\section{Baseline data}

Baseline values of spontaneous pulmonary function variables ( $V \mathrm{~T}, C$ dyn, $R \mathrm{~L}$ ) were not significantly different between the treatment groups (table 2). Of the forced lung function variables, only FEF75 and FEF25 were significantly different in "high terbutaline" rats and controls $(\mathrm{p}<0.05)$ (table 2$)$, which was probably due to chance. FRC was significantly higher in "high terbutaline" animals $(\mathrm{p}<0.05)$ (data not shown). Lung function variables were in the normal range for this laboratory.

\section{Effect of treatment on unchallenged pulmonary function}

The various treatment regimens did not change spontaneous respiratory function variables and forced expiratory manoeuvres (table 2), except that dynamic compliance (delta value) decreased less in the high terbutaline-treated group compared to the control group $(p<0.05)$. Of the lung volumes, only RV appeared to decrease in the surfactant-treated animals $(\mathrm{p}<0.05)$ (data not shown).

\section{Effect of treatment on acetylcholine challenge}

ACh aerosol increased $R \mathrm{~L}$ and decreased $C$ dyn and $V \mathrm{~T}$ in all groups $(\mathrm{p}<0.01)$ (for absolute values see table 2 ). In vehicle-treated animals, ACh challenge increased RL by $64 \pm 8 \%$. In "high terbutaline" and surfactant-treated animals, the increases in $R \mathrm{~L}$ were $36 \pm 7 \%(\mathrm{p}<0.05)$ and $34 \pm 5 \%(p<0.01)$, respectively, significantly less than in the controls (fig. 1). Combined terbutaline and surfactant also inhibited the increase of $R \mathrm{~L}(40 \pm 7 \%$; $\mathrm{p}<0.05)$, but there was no evidence of an additive effect. Of the forced expiratory variables, only FVC and forced expiratory volume in four hundred milliseconds (FEV0.4) (delta \% of prechallenge values) decreased significantly less in surfactant-treated animals compared to controls $(\mathrm{p}<0.05)$ (table 3).

\section{Intravenous acetylcholine challenge}

Intravenous ACh raised RL by $166 \pm 26,160 \pm 6$, and $131 \pm 13 \%$ in the animals which subsequently received

Table 2. - Spontaneous respiratory function variables and forced expiratory flow-volume data in baseline conditions, after treatment with the test compounds, and after acetylcholine challenge

\begin{tabular}{|c|c|c|c|c|c|}
\hline & Control & Low terbutaline & High terbutaline & Surfactant & Combination \\
\hline \multicolumn{6}{|l|}{ Baseline } \\
\hline$V \mathrm{~T} \quad \mathrm{~mL}$ & $1.51 \pm 0.05$ & $1.47 \pm 0.05$ & $1.50 \pm 0.09$ & $1.45 \pm 0.05$ & $1.58 \pm 0.05$ \\
\hline$C$ dyn $\mathrm{mL} \cdot \mathrm{cmH}_{2} \mathrm{O}^{-1}$ & $0.24 \pm 0.02$ & $0.26 \pm 0.02$ & $0.20 \pm 0.02$ & $0.22 \pm 0.01$ & $0.24 \pm 0.02$ \\
\hline$R \mathrm{~L} \quad \mathrm{cmH}_{2} \mathrm{O} \cdot \mathrm{mL}^{-1} \cdot \mathrm{s}^{-1}$ & $0.22 \pm 0.01$ & $0.20 \pm 0.02$ & $0.23 \pm 0.01$ & $0.23 \pm 0.01$ & $0.22 \pm 0.02$ \\
\hline FVC mL & $14.0 \pm 0.53$ & $13.8 \pm 0.68$ & $12.8 \pm 0.53$ & $12.7 \pm 0.64$ & $14.4 \pm 0.87$ \\
\hline $\mathrm{PEF} \quad \mathrm{mL} \cdot \mathrm{s}^{-1}$ & $109.0 \pm 2.3$ & $107.5 \pm 3.1$ & $115.7 \pm 2.8$ & $105.4 \pm 1.6$ & $111.4 \pm 2.5$ \\
\hline MMEF $\mathrm{mL} \cdot \mathrm{s}^{-1}$ & $94.5 \pm 2.6$ & $95.6 \pm 2.8$ & $87.5 \pm 1.67$ & $89.6 \pm 1.7$ & $92.0 \pm 2.7$ \\
\hline FEF75 $\mathrm{mL} \cdot \mathrm{s}^{-1}$ & $105.0 \pm 2.4$ & $102.1 \pm 3.6$ & $113.7 \pm 2.4^{*}$ & $99.9 \pm 2.2$ & $108.0 \pm 2.5$ \\
\hline FEF50 $\mathrm{mL} \cdot \mathrm{s}^{-1}$ & $105.8 \pm 2.4$ & $105.8 \pm 3.2$ & $99.5 \pm 3.8$ & $100.9 \pm 1.7$ & $104.4 \pm 3.1$ \\
\hline $\mathrm{FEF} 25 \mathrm{~mL} \cdot \mathrm{s}^{-1}$ & $61.2 \pm 2.7$ & $63.0 \pm 2.5$ & $51.1 \pm 2.0^{*}$ & $57.5 \pm 3.1$ & $55.4 \pm 2.4$ \\
\hline $\mathrm{FEV}_{0.1} \mathrm{~mL}$ & $8.8 \pm 0.22$ & $8.6 \pm 0.34$ & $8.7 \pm 0.16$ & $8.2 \pm 0.21$ & $8.8 \pm 0.24$ \\
\hline \multicolumn{6}{|l|}{ After treatment } \\
\hline$V \mathrm{~T} \quad \mathrm{~mL}$ & $1.43 \pm 0.04$ & $1.42 \pm 0.06$ & $1.41 \pm 0.06$ & $1.39 \pm 0.04$ & $1.52 \pm 0.05$ \\
\hline$C_{\text {dyn }} \mathrm{mL} \cdot \mathrm{cmH}_{2} \mathrm{O}^{-1}$ & $0.20 \pm 0.01$ & $0.21 \pm 0.01$ & $0.18 \pm 0.02$ & $0.18 \pm 0.01$ & $0.22 \pm 0.02$ \\
\hline$R \mathrm{~L} \quad \mathrm{cmH}_{2} \mathrm{O} \cdot \mathrm{mL}^{-1} \cdot \mathrm{s}^{-1}$ & $0.23 \pm 0.01$ & $0.22 \pm 0.01$ & $0.23 \pm 0.01$ & $0.23 \pm 0.01$ & $0.22 \pm 0.02$ \\
\hline $\mathrm{FVC} \mathrm{mL}^{2}$ & $13.5 \pm 0.65$ & $13.6 \pm 0.74$ & $12.7 \pm 0.55$ & $11.8 \pm 0.63$ & $14.4 \pm 0.89$ \\
\hline $\mathrm{PEF} \quad \mathrm{mL} \cdot \mathrm{s}^{-1}$ & $116.3 \pm 2.1$ & $117.7 \pm 3.3$ & $116.3 \pm 3.2$ & $11.0 \pm 2.5$ & $116.7 \pm 1.6$ \\
\hline MMEF $\mathrm{mL} \cdot \mathrm{s}^{-1}$ & $88.8 \pm 2.4$ & $94.3 \pm 3.8$ & $81.3 \pm 7.6$ & $82.2 \pm 5.2$ & $86.6 \pm 3.3$ \\
\hline FEF75 $\mathrm{mL} \cdot \mathrm{s}^{-1}$ & $113.7 \pm 2.1$ & $114.3 \pm 3.3$ & $115.2 \pm 3.0$ & $109.0 \pm 2.4$ & $114.3 \pm 1.4$ \\
\hline FEF50 $\mathrm{mL} \cdot \mathrm{s}^{-1}$ & $100.6 \pm 4.1$ & $106.8 \pm 4.8$ & $92.8 \pm 7.4$ & $90.6 \pm 6.2$ & $98.2 \pm 4.4$ \\
\hline $\mathrm{FEF} 25 \mathrm{~mL} \cdot \mathrm{s}^{-1}$ & $51.6 \pm 2.7$ & $57.7 \pm 3.5$ & $44.6 \pm 6.1$ & $48.7 \pm 4.2$ & $48.4 \pm 2.9$ \\
\hline $\mathrm{FEV}_{0.1} \quad \mathrm{~mL}$ & $8.7 \pm 0.27$ & $9.1 \pm 0.38$ & $8.3 \pm 0.47$ & $7.9 \pm 0.24$ & $9.0 \pm 0.31$ \\
\hline \multicolumn{6}{|l|}{ After challenge } \\
\hline$V$ T $\mathrm{mL}$ & $1.20 \pm 0.05$ & $1.21 \pm 0.06$ & $0.23 \pm 0.05$ & $1.24 \pm 0.05$ & $1.30 \pm 0.05$ \\
\hline$C$ dyn $\mathrm{mL} \cdot \mathrm{cmH}_{2} \mathrm{O}^{-1}$ & $0.12 \pm 0.01$ & $0.13 \pm 0.01$ & $0.13 \pm 0.01$ & $0.15 \pm 0.01$ & $0.13 \pm 0.02$ \\
\hline$R \mathrm{~L} \quad \mathrm{cmH}_{2} \mathrm{O} \cdot \mathrm{mL}^{-1} \cdot \mathrm{s}^{-1}$ & $0.33 \pm 0.02$ & $0.30 \pm 0.02$ & $0.31 \pm 0.02$ & $0.29 \pm 0.02$ & $0.30 \pm 0.03$ \\
\hline $\mathrm{FVC} \mathrm{mL}$ & $10.8 \pm 0.92$ & $12.0 \pm 1.00$ & $11.6 \pm 0.61$ & $11.0 \pm 0.43$ & $12.8 \pm 0.88$ \\
\hline $\mathrm{PEF} \quad \mathrm{mL} \cdot \mathrm{s}^{-1}$ & $110.0 \pm 2.5$ & $115.3 \pm 3.2$ & $114.2 \pm 4.2$ & $106.8 \pm 2.9$ & $111.4 \pm 3.1$ \\
\hline MMEF $\mathrm{mL} \cdot \mathrm{s}^{-1}$ & $77.8 \pm 4.3$ & $83.5 \pm 4.4$ & $72.3 \pm 7.1$ & $75.8 \pm 4.4$ & $76.4 \pm 4.6$ \\
\hline FEF75 $\mathrm{mL} \cdot \mathrm{s}^{-1}$ & $108.2 \pm 2.4$ & $113.4 \pm 2.8$ & $112.5 \pm 4.2$ & $104.6 \pm 3.0$ & $109.8 \pm 3.1$ \\
\hline FEF50 $\mathrm{mL} \cdot \mathrm{s}^{-1}$ & $87.4 \pm 5.6$ & $92.9 \pm 5.5$ & $81.1 \pm 6.0$ & $85.3 \pm 4.8$ & $85.7 \pm 5.6$ \\
\hline $\mathrm{FEF} 25 \mathrm{~mL} \cdot \mathrm{s}^{-1}$ & $42.6 \pm 3.1$ & $45.6 \pm 3.4$ & $37.2 \pm 5.7$ & $44.1 \pm 3.8$ & $42.0 \pm 3.9$ \\
\hline FEV0.1 mL & $7.5 \pm 0.45$ & $8.2 \pm 0.44$ & $7.4 \pm 0.50$ & $7.7 \pm 0.23$ & $8.2 \pm 0.36$ \\
\hline
\end{tabular}

Absolute values are presented as mean \pm SEM. $V$ T: tidal volume; $C$ dyn: dynamic compliance; $R \mathrm{~L}$ : lung resistance; FVC: forced vital capacity; PEF: peak expiratory flow; MMEF: mean midexpiratory flow; FEF75, FEF50 and FEF25: forced expiratory flow at 75, 50 and $25 \%$ FVC, respectively; FEV0.1: forced expiratory volume in one hundred milliseconds. *: $\mathrm{p}<0.05$, compared to control group. 


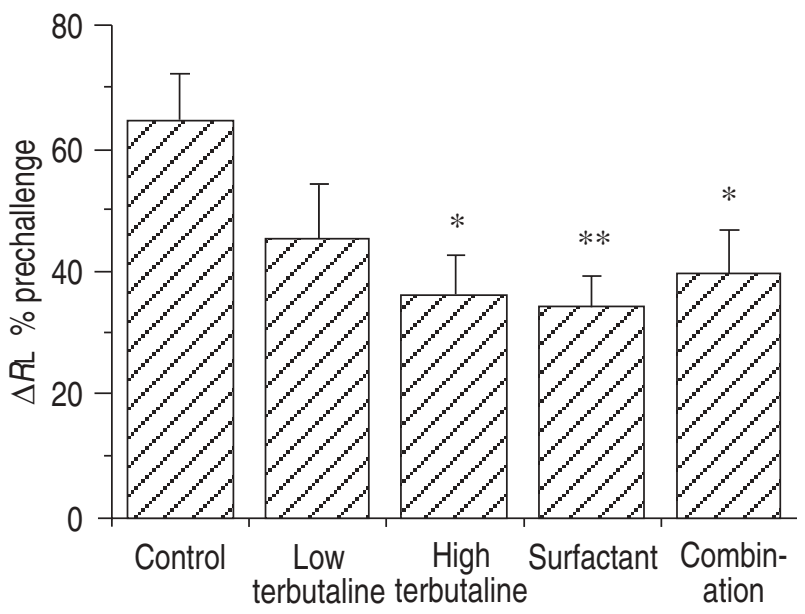

Fig. 1. - Increase of lung resistance ( $\Delta R \mathrm{~L} \%$ of prechallenge) after inhalative acetylcholine challenge in rats treated with aerosolized vehicle (control), a low concentration of terbutaline (low terbutaline), a high concentration of terbutaline (high terbutaline), surfactant (surfactant), and combined low terbutaline with surfactant (combination). Values are presented as mean \pm SEM $(\mathrm{n}=5-9)$. *: $\mathrm{p}<0.05 ; * *: \mathrm{p}<0.01$, compared to control group.

terbutaline, surfactant and control aerosols, respectively $(n=4$ each). These changes were not significantly different from one another. After treatment, a second intravenous ACh challenge increased $R \mathrm{~L}$ significantly less in terbutaline-treated rats $(\Delta R \mathrm{~L} 123 \pm 17 \%$; $\mathrm{p}<0.05)$, but the responses were essentially unchanged in surfactanttreated animals $(\Delta R \mathrm{~L} 153 \pm 3 \%)$ and in the control group $(\Delta R \mathrm{~L} 132 \pm 7 \%)$. Thus, terbutaline treatment significantly reduced the increase in $R \mathrm{~L}$ resulting from i.v. ACh challenge to $75 \pm 2 \%$ of the baseline ACh re-sponse. The equivalent figures after surfactant and control aerosols were $97 \pm 6$ and $102 \pm 6 \%$ of the baseline response, respectively (fig. 2).

\section{Surface activity}

There was no significant difference in surface activity between "aerosolized" and "diluted" surfactant. Minimum surface tensions were $4.2 \pm 5.5$ and $2.8 \pm 2.9 \mathrm{mN} \cdot \mathrm{m}^{-1}$, respectively $(n=6-8)$.

Table 3. - Respiratory function variables and forced expiratory flowvolume data after acetylcholine challenge

\begin{tabular}{lrcccr}
\hline & Control & $\begin{array}{c}\text { Low } \\
\text { terbutaline }\end{array}$ & $\begin{array}{c}\text { High } \\
\text { terbutaline }\end{array}$ & Surfactant & Combination \\
\hline$V \mathrm{~T}$ & $-15.0 \pm 2.3$ & $-12.1 \pm 2.8$ & $-9.2 \pm 3.7$ & $-7.4 \pm 2.4$ & $-10.8 \pm 1.8$ \\
Cdyn & $-47.5 \pm 2.9$ & $-39.8 \pm 4.4$ & $-30.9 \pm 8.9$ & $-36.5 \pm 3.7$ & $-40.6 \pm 5.1$ \\
$R \mathrm{~L}$ & $+64.5 \pm 7.5$ & $+45.2 \pm 8.9$ & $+36.0 \pm 6.8 *$ & $+34.3 \pm 4.9 * *$ & $+39.7 \pm 7.1 *$ \\
FVC & $-20.7 \pm 4.2$ & $-12.4 \pm 4.7$ & $-8.2 \pm 2.4$ & $-5.6 \pm 3.3 *$ & $-10.6 \pm 2.0$ \\
PEF & $-5.3 \pm 1.8$ & $-1.8 \pm 2.2$ & $-1.8 \pm 2.4$ & $-3.7 \pm 1.5$ & $-4.5 \pm 2.5$ \\
MMEF & $-12.7 \pm 3.4$ & $-11.2 \pm 3.8$ & $-11.2 \pm 3.0$ & $-7.1 \pm 3.1$ & $-12.1 \pm 2.9$ \\
FEF75 & $-4.7 \pm 2.1$ & $-0.5 \pm 2.5$ & $-2.4 \pm 2.2$ & $-4.0 \pm 1.7$ & $-3.9 \pm 2.9$ \\
FEF50 & $-13.4 \pm 3.0$ & $-12.8 \pm 3.8$ & $-12.2 \pm 3.7$ & $-4.8 \pm 3.4$ & $-12.9 \pm 3.4$ \\
FEF25 & $-17.2 \pm 5.0$ & $-20.5 \pm 4.9$ & $-17.4 \pm 3.5$ & $-9.1 \pm 2.2$ & $-13.7 \pm 5.0$ \\
FEV0.1 & $-14.2 \pm 4.0$ & $-8.3 \pm 4.2$ & $-10.4 \pm 3.4$ & $-1.7 \pm 2.0$ & $-9.1 \pm 1.9$ \\
FEV0.4 & $-20.7 \pm 4.1$ & $-13.0 \pm 4.5$ & $-9.0 \pm 2.5$ & $-5.4 \pm 3.1 *$ & $-11.6 \pm 2.2$ \\
\hline
\end{tabular}

Values are presented as change in $\%$ of predicted values and are expressed as mean \pm SEM. FEV0.4: forced expiratory volume in four hundred milliseconds. For further abbreviations see legend to table 2 . *: $\mathrm{p}<0.05$; **: $\mathrm{p}<0.01$, compared to control.

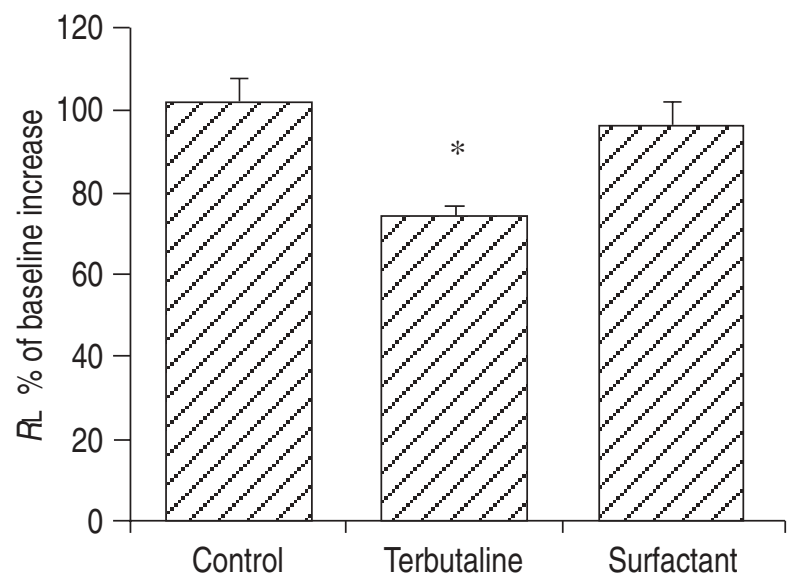

Fig. 2. - Lung resistance $(R \mathrm{~L})$ induced by intravenous acetylcholine $\mathrm{ACh}$ ) after treatment with aerosolized vehicle (control), a high concentration of terbutaline (terbutaline), and surfactant (surfactant), expressed as \% of baseline increase of $R \mathrm{~L}$ after ACh challenge. Values are presented as mean $\pm \operatorname{SEM}(n=4) . *: p<0.05$, compared to control group.

\section{Discussion}

The present data confirm previous findings in animals and humans that exogenous surfactant treatment inhibits airway obstruction [9-11]. In detail, these results show that treatment with an aerosol of surfactant lessens the increase in airway resistance in response to subsequent ACh challenge when this was by aerosol. Treatment with terbutaline aerosol was similarly effective against ACh challenge. Simultaneous terbutaline and surfactant treatments were no more effective against challenge by $\mathrm{ACh}$ aerosol than surfactant treatment alone. When subsequent ACh challenge was by the intravenous route, however, terbutaline treatment still lessened the rise in airway resistance, but surfactant aerosol did not.

Several mechanisms could account for the difference in effectiveness of airway surfactant against ACh challenge by the two routes. One likely mechanism is that surfactant may line the airways with a lipophilic layer, which would act as a diffusion barrier to the absorption of hydrophilic molecules, such as ACh. Intravenous $\mathrm{ACh}$, on the other hand, would reach the airway smooth muscle directly, without crossing the lipophilic layer of surfactant. This explanation would, in addition, account for the failure of simultaneous treatment with terbutaline, which is hydrophilic, to increase surfactant's protection against aerosol challenge with ACh; surfactant would also impose a barrier to terbutaline absorption. This hypothesis is supported by experiments showing that exogenous surfactant components seem to adhere to epithelial surfaces. Following intratracheal administration of radiolabelled surfactant in vivo, only 50-70\% of the labelled phospholipids (PLs) were recovered by bronchoalveolar lavage [16, 17]. The labelled lipids were not detectable in lamellar bodies but seemed to be associated with lung tissue [18], thus suggesting adherence to the airway epithelium. 
The view of a "surfactant barrier" in the airways is further supported by the observation that in surfactantdepleted rats, subsequent intratracheal administration of adrenaline induced augmented haemodynamic effects when compared to nondepleted animals [19]. Moreover, in a preliminary in vitro study, we have shown that surfactant has a protective effect on ozone-induced oxidative damage in type II pneumocytes and alveolar macrophages [20]. Furthermore, there is growing evidence that the gastro-intestinal mucosa is protected against diffusion of hydrophilic molecules (luminal acid) by a physical barrier comprising surface-active PLs [21-23]. These surface-active PLs cause surface hydrophobicity and lie on top of the mucous gel that covers the epithelium [24]. In the airways, an additional luminal surfactant layer on top of the mucous layer has been proposed by GERDE et al. [25]. The possible role of surfactant as an airway receptor barrier has recently been highlighted by HiLLs [26].

Surfactant may also inhibit the action of ACh by catalysing its hydrolysis within the airway lumen before it can reach airway smooth muscle. This explanation would account for surfactant's ability to protect against the rise in $R \mathrm{~L}$ in response to $\mathrm{ACh}$ challenge by aerosol but not by the intravenous route; however, it would not explain the lack of an additive protective effect of combined terbutaline and surfactant. Such interactions of surfactant with pharmacological agents have been shown in vitro as a modulation of bactericidal activity of antibiotic drugs [27].

Another possible explanation is that surfactant has a direct effect on ACh-induced mucosal oedema because surfactant is important for alveolar and airway fluid balance $[28,29]$. Thus, exogenous surfactant could, in part, reverse fluid imbalance, thereby lessening airway wall thickness. This could account for reduced lung resistance in response to $\mathrm{ACh}$ after surfactant treatment in the present study. Furthermore, ACh challenge could have led to secretion of mucus and influx of proteinaceous fluid into the airways with inhibition of proper surfactant function. Impairment of airway surfactant function might have been reversed by exogenous surfactant treatment, preventing airway narrowing and collapse. Neither explanation, however, would explain the failure of surfactant to prevent airway obstruction to subsequent ACh challenge by the intravenous route.

Surfactant inhalation improved respiratory function in asthmatic humans at doses as low as $10 \mathrm{mg}$ [11]. Deposition studies with inhaled surfactant in adults revealed an endobronchial deposition rate of only $2 \%$ [30]. However, higher doses were required when surfactant was administered by the intratracheal route $[9,10]$. The animals in the present study inhaled about $100 \mu \mathrm{g} \cdot \mathrm{kg}^{-1}$ surfactant. Experiments by RAABE et al. [31] have shown that bronchial and alveolar deposition of aerosols with particles of $1.3 \mu \mathrm{m}$ is about $30 \%$ in rats. Thus, the effective surfactant dose in the present experiments might have been as low as $30 \mu \mathrm{g} \cdot \mathrm{kg}^{-1}$. Assuming an alveolar surfactant pool of $10-15 \mathrm{mg}$ phospholipids $\cdot \mathrm{kg}^{-1}$ body weight [32], or a surfactant concentration of the epithelial lining fluid of about $24 \mathrm{mg}$ phospholipids $\cdot \mathrm{mL}^{-1}$ [33], and estimating the total volume of subphase fluid in which surfactant is suspended with $6-12 \mathrm{~mL} \cdot \mathrm{L}^{-1}$ of TLC volume according to EFFros et al. [34], the increase of surfactant concentration in the lining layer due to treat- ment would have been as low as $0.4 \%$ in the present study. This implies that small increases of airway surfactant might induce large protective effects against exogenous bronchoconstrictor stimuli.

In summary, we suggest that surfactant may act as a diffusion barrier to the absorption of exogenous hydrophilic molecules, and that its inhibitory effect possibly includes an interaction of surfactant with pharmacological agents in the airway lumen. The amount of exogenous surfactant required to influence airway calibre seems to be far less compared to that used for established surfactant therapies, such as in respiratory distress syndrome. Further investigations are needed to elucidate the underlying mechanisms of the surfactant effect observed. In particular, the effect of surfactant on drug absorption across the airway epithelium should be measured. Additionally, further studies have to be conducted to establish whether inhaled surfactant has clinical benefits in obstructive lung disorders.

Acknowledgements: The technical assistance of M. Mälzer is gratefully acknowledged. The authors thank M.M. Höper for criticizing the draft and proofreading the manuscript. Alveofact ${ }^{\circledR}$ was a generous gift from Dr Karl Thomae GmbH, Biberach an der Riss, Germany.

\section{References}

1. Macklem PT, Proctor DF, Hogg JC. The stability of peripheral airways. Respir Physiol 1970; 8: 191-203.

2. Liu M, Wang L, Li E, Enhorning G. Pulmonary surfactant will secure free airflow through a narrow tube. J Appl Physiol 1991; 71: 742-748.

3. Enhorning G, Duffy LC, Welliver RC. Pulmonary surfactant maintains patency of conducting airways in the rat. Am J Respir Crit Care Med 1995; 151: 554-556.

4. Hohlfeld J, Fabel H, Hamm H. The role of pulmonary surfactant in obstructive airways disease. Eur Respir $J$ 1997; 10: 482-491.

5. Schürch S, Gehr P, Im Hof V, Geiser M, Green F. Surfactant displaces particles toward the epithelium in airways and alveoli. Respir Physiol 1990; 80: 17-32.

6. van Iwaarden JF. Surfactant and the pulmonary defense system. In: Robertson B, van Golde LMG, Batenburg JJ, eds. Pulmonary Surfactant. From Molecular Biology to Clinical Practice. Amsterdam-London-New YorkTokyo, Elsevier, 1992; pp. 215-227.

7 . McFadden ERJ, Gilbert IA. Asthma. N Engl J Med 1992; 327: 1928-1937.

8. Seeger W, Grube C, Günther A, Schmidt R. Surfactant inhibition by plasma proteins: differential sensitivity of various surfactant preparations. Eur Respir J 1993; 6: 971-977.

9. Becher G. Lung surfactant prevents allergic bronchial constriction in ovalbumin sensitized guinea-pigs. Biomed Biochim Acta 1985; 44: K57-K61.

10. Liu M, Wang L, Li E, Enhorning G. Pulmonary surfactant given prophylactically alleviates an asthma attack in guinea-pigs. Clin Exp Allergy 1996; 26: 270-275.

11. Kurashima K, Ogawa H, Ohka T, Fujimura M, Matsuda T, Kobayashi T. A pilot study of surfactant inhalation in the treatment of asthmatic attack. Aerugi (Jpn J Allergol) 1991; 40: 160-163. 
12. Hoymann HG, Heinrich U, Beume R, Kilian U. Comparative investigation of the effects of zardaverine and theophylline on pulmonary function in rats. Exp Lung Res 1994; 20: 235-250.

13. Flüge T, Hoymann HG, Hohlfeld J, et al. Type A natriuretic peptide exhibits different bronchoprotective effects in rats. Eur J Pharmacol 1994; 271: 395-402.

14. Enhorning G. Pulsating bubble technique for evaluating pulmonary surfactant. J Appl Physiol: Respirat Environ Exercise Physiol 1977; 43: 198-203.

15. Snedecor GW, Cochran WG. One-way classifications: analysis of variance. In: Statistical methods. 6th Edn. Ames (Iowa), Iowa State University Press, 1967; pp. 258-298.

16. Wright JR, Wager RE, Hamilton RL, Huang M, Clements JA. Uptake of lung surfactant subfractions into lamellar bodies of adult rabbit lungs. J Appl Physiol 1986; 60: 817-825.

17. Pettenazzo A, Jobe A, Ikegami M, Abra R, Hogue E, Mihalko P. Clearance of phosphatidylcholine and cholesterol from liposomes, liposomes loaded with metaproterenol, and rabbit surfactant from adult rabbit lungs. Am Rev Respir Dis 1989; 139: 752-758.

18. Jacobs H, Jobe A, Ikegami M, Jones S. Surfactant phosphatidylcholine sources, fluxes, and turnover times in 3 day old, 10 day old, and adult rabbits. J Biol Chem 1982; 257: 1805-1810.

19. So KL, Gommers D, Lachmann B. Bronchoalveolar surfactant and intratracheal adrenaline. Lancet 1993; 341: 120-121.

20. Schürmann WHT, Hohlfeld J, Muhle H, Fabel H. Oxidative damage of rat type II pneumocytes and alveolar macrophages: protective effect of surfactant. Eur Respir $J$ 1995; 8: 464s.

21. Lichtenberger LM, Graziani LA, Dial EJ, Butler BD, Hills BA. Role of surface active phospholipids in gastric cytoprotection. Science 1983; 219: 1327-1329.

22. Lugea A, Mourelle M, Guarner F, Domingo A, Salas A, Malagelada JR. Phosphatidylcholines as mediators of adaptive cytoprotection of the rat duodenum. Gastroenterology 1994; 107: 720-727.
23. Hills BA. Oesophageal surfactant: evidence for a possible mucosal barrier on oesophageal epithelium. Aust NZ J Med 1994; 24: 41-46.

24. Goddard PJ, Kao YJ, Lichtenberger LM. Luminal surface hydrophobicity of canine gastric mucosa is dependent on a surface mucous gel. Gastroenterology 1990; 98:361-370.

25. Gerde P, Muggenburg BA, Sabourin PJ, et al. Disposition of polycyclic aromatic hydrocarbons in the respiratory tract of the beagle dog. II. The conducting airways. Toxicol Appl Pharmacol 1993; 121: 319-327.

26. Hills BA. Asthma: is there an airway receptor barrier? Thorax 1996; 51: 773-776.

27. van't Veen A, Mouton JW, Gommers D, Kluytmans JA, Dekkers P, Lachmann B. Influence of pulmonary surfactant on in vitro bactericidal activities of amoxycillin, ceftazidime and tobramycin. Antimicrob Agents Chemother 1995; 39: 329-333.

28. Bredenberg CE, Paskanik AM, Nieman GF. High surface tension pulmonary edema. J Surg Res 1983; 34: 515-523.

29. Kaneko T, Sato T, Katsuya H, Miyauchi Y. Surfactant therapy for pulmonary edema due to intratracheallyinjected bile acid. Crit Care Med 1990; 18: 77-83.

30. Oetomo SB, Dorrepaal C, Bos H, et al. Surfactant nebulization does not alter airflow obstruction and bronchial responsiveness to histamine in asthmatic children. Am J Respir Crit Care Med 1996; 153: 1148-1152.

31. Raabe OG, Al-Bayati MA, Teague SV, Rasolt A. Regional deposition of inhaled monodisperse coarse and fine aerosol particles in small laboratory animals. Ann Occup Hyg 1988; 32: 53-63.

32. Jobe A, Ikegami M. Surfactant for the treatment of respiratory distress syndrome. Am Rev Respir Dis 1987; 136: $1256-1275$.

33. Mason RJ. Surfactant secretion. In: Robertson B, van Golde LMG, Batenburg JJ, eds. Pulmonary Surfactant: From Molecular Biology to Clinical Practice. AmsterdamLondon-New York-Tokyo, Elsevier, 1992: pp. 295-312.

34. Effros RM, Feng NH, Mason G, Sietsema K, Silverman $\mathrm{P}$, Hukkanen J. Solute concentrations of pulmonary epithelial lining fluid of anesthetized rats. J Appl Physiol 1990; 68: 275-281. 